\title{
MS37-03 | 1H, 19F AND 29SI MAS NMR INVESTIGATIONS OF SYNTHETIC LEPIDOLITE SAMPLES WITH VARIABLE OH/F RATIOS
}

Sulcek, Lara (Ruhr-Universität Bochum, Bochum, GER); Fechtelkord, Michael (Ruhr-Universität Bochum, Bochum, GER)

${ }^{1} \mathrm{H},{ }^{29} \mathrm{Si}$ and ${ }^{19} \mathrm{~F}$ solid state NMR spectroscopic, infrared spectroscopic and $\mathrm{X}$-ray diffraction experiments were performed to investigate the cationic and anionic ordering in the octahedral and tetrahedral sheets in the system trilithionite - polylithionite with composition $\mathrm{K}\left(\mathrm{Li}_{\mathrm{x}} \mathrm{Al}_{3-\mathrm{x}}\right)\left[\mathrm{Al}_{4-2 x} \mathrm{Si}_{2 x} \mathrm{O}_{10}\right]\left(\mathrm{F}_{2-y}, \mathrm{OH}_{y}\right)(1.5 \leq \mathrm{x} \leq 2.0 ; 0.0 \leq \mathrm{y} \leq 1.4)$.

The influence of the different $\mathrm{OH} / \mathrm{F}$ ratios on the composition of octahedral and tetrahedral layers and the resulting formation of secondary phases were considered. In addition, bonding preferences from $\mathrm{F}$ to Li-cations and $\mathrm{OH}$ to Al-cations should be elucidated. The changes in the tetrahedral and octahedral sheets and the relation to each other is another aspect of this work.

There are strong indications that signals from different polytypes can be separated in the ${ }^{19} \mathrm{~F}$ MAS NMR spectra. Furthermore the X-ray diffraction experiments confirm the appearance of the polytypes $1 M$ and $2 M_{1}$. The percentage of both polytypes can be calculated by using the signal areas of the ${ }^{19} \mathrm{~F}$ MAS NMR spectra. It can be shown, that the ratio of the polytypes is independent of the composition according to Heinrich (1967). Furthermore, the ${ }^{19} \mathrm{~F}$ MAS NMR spectra show an F preference to Li-rich octahedral clusters and in contrast to this the ${ }^{1} \mathrm{H}$ MAS NMR spectra reveal the location of OH-groups in the Al-rich octahedral clusters.

[1] Heinrich, E.W. (1967) American Mineralogist, 52, 1110-1121. 